\title{
Short Communication: Agro-morphological diversity among four tomato cultivars in western Burundi
}

\author{
FREDERIC NGEZAHAYO ${ }^{1, \bullet}$, JEAN CLAUDE NGENDAKURIYO ${ }^{1}$, EMMANUEL BIZINDAVYI ${ }^{1}$, \\ CYRILLE MBONIHANKUYE ${ }^{2}$ \\ ${ }^{1}$ Unité de Recherche en Sciences Naturelles, Département des Sciences Naturelles, Ecole Normale Supérieure. BP 6983, Bujumbura, Burundi. \\ Tel. +257-71-986 062, `email: ngezafre@ yahoo.fr \\ ${ }^{2}$ Service de Valorisation des Résultats de la Recherche, Institut des Sciences Agronomiques du Burundi (ISABU). BP 795, Bujumbura, Burundi
}

Manuscript received: 7 January 2019. Revision accepted: 23 January 2019.

\begin{abstract}
Ngezahayo F, Ngendakuriyo Jc, Bizindavyi E, Mbonihankuye C. 2019. Short Communication: Agro-morphological diversity among four tomato cultivars in western Burundi. Biodiversitas 20: 436-441. Since crop cultivars represent a reservoir of genetic diversity; essential are the understanding and the utilization of genetic variation in tomato accessions for improving the crop. The objective of the present study was to characterize 4 tomato cultivars from the western Burundi by means of 8 agro-morphological traits that could be exploited for tomato crop improvement. Tanya and P20 cultivars showed the lowest plant height but the highest flower number, fruit number and yield per cultivar. This was corroborated by a significant negative correlation between plant height and flower number, fruit number and yield per cultivar in overall results. On the other hand, Floradel and Tengerou97 cultivars have the highest stem circumference and leaf number. Cluster analysis also showed almost four clusters corresponding to one cluster for each cultivar, though Tengerou97 and Floradel tend to be grouped together. Finally, principal component analysis showed that all the eight agromorphological traits participated in grouping tomato cultivars; particularly flower number, fruit number, plant height, and yield per cultivar. The first three principal component axes accounted for $92.465 \%$ of total variation observed among tomato cultivars. Thus, the four cultivars should all be exploited in tomato breeding and improvement programs.
\end{abstract}

Keywords: Agro-morphological traits, Burundi, cultivars, genetic diversity, Solanum lycopersicum

\section{INTRODUCTION}

After potato, tomato (Solanum lycopersicum L.) is ranking as one of the most important cultivated vegetables and the second consumed, with a worldwide production level of more than 170 million tons in 2014 (FAO 2017). Tomato is also the second most important legume after potato in tropical regions (Fuseini 2010; Al-Aysh et al. 2012). Solanum lycopersicum belongs to the Solanaceae family and is characterized by its diploidy $(2 n=2 x=24)$ with $950 \mathrm{Mb}$ in size (Arumuganathan and Earle 1991). Its worldwide popularity is due to its high consumption, availability, and health benefits (Isah et al. 2014). Although tomato is low in energy and protein, it is rich in vitamins A, $\mathrm{C}$, and $\mathrm{E}$, and in lycopene which is recognized for its role in human health and chronic diseases (Agarwal and Rao 2000).

Cultivation age of tomato being around 400 years, this crop plant was introduced from the center of origin in Central and Southern America to Europe and later on to Africa where it ranks among the most consumed and domesticated fruit vegetables (Ogwu et al. 2016). In Burundi, cultivation of tomato is known since the $20^{\text {th }}$ century but was intensified in 1977 after a particular consent between Belgium cooperation and the Republic of Burundi. It is, since that time, intensively and largely cultivated for its fruits in warm regions such as IMBO and
KUMOSO (unpublished data).

Variability identification among accessions is of high importance to the maintenance and utilization of genetic resources (Mwirigi et al. 2009) and it is known that evaluation of germplasm is very important for the plant improvement program (Reddy et al. 2013). Among the methods used to identify and estimate the genetic diversity of plants, morphological or agro-morphological traits are important diagnostic characteristics for distinguishing genotypes (Osei et al. 2014). That is why morphological traits have been widely used in the assessment of variability within different plant species including rice (Caldo et al. 1996), Carthamus tinctorius L. (Shinwari et al. 2014), Iris (Azimi et al. 2016), wheat (Bellatreche et al. 2017), Psidium guajava L. (Kidaha et al. 2015), Capsicum sp. (Agyare et al. 2016), Solanum macrocarpon L. (Saka et al. 2017), Arachis hypogaea L. (Neya et al. 2018), common bean (Boros et al. 2014), Hoary cress (Roughani et al. 2018), and Bidens pilosa L. (Ngezahayo et al. 2018). Although genetic variation in tomato by morphological features has been the subject of many studies around the world (Agong et al. 2001, Mazzucato et al. 2008, Al-Aysh et al. 2012, Osei et al. 2014, Chime et al. 2017; Yadav et al. 2017; Kouam et al. 2018), no work on cultivated tomato in Burundi has been conducted to our knowledge. The objective of the present work was to characterize cultivated tomato cultivars from western Burundi using agro- 
morphological markers which may be potentially useful for breeding and improvement program.

\section{MATERIALS AND METHODS}

\section{Study area}

Seeds of four tomato cultivars widely cultivated in Western Burundi, i.e., Tanya, P20, Floradel and Tengerou97, were provided by the Institute of Agronomic Sciences of Burundi (Institut des Sciences Agronomiques $\mathrm{du}$ Burundi, ISABU). The experimental research was carried out from November 2016 to March 2017 in the field of the ISABU institute, in the rainy season. The site of experimental research is located $\left(03^{\circ} 39.333^{\prime} \mathrm{N}\right.$ latitude, $029^{\circ} 36.457^{\prime} \mathrm{E}$ longitude, and at $810 \mathrm{~m}$ of altitude) in the IMBO natural region with a semi-arid climate. During the plant growth period, average rainfall, temperature, and humidity were respectively $114.9 \mathrm{~mm}, 25.29^{\circ} \mathrm{C}$, and $70.3 \%$.

\section{Procedures}

Soil texture of the station was sandy loamy with $\mathrm{pH} 6.8$, and the nursery was installed with well-decomposed cow dung. Transplanting of tomato seedlings was 4 weeks after sowing. The experiments were arranged in a randomized complete blocks design with three replicates (Figure 1).

Each block consisted of four experimental units of $4 \mathrm{~m}^{2}$ area each. Each experimental unit contained a randomly selected cultivar consisting of 8 individuals arranged in two rows of four plants each. Agronomic practices consisting of weeding were carried out to provide plants with adequate growth conditions. Eight plants were sampled for each experimental unit for analysis of agro-morphological traits. A total of twenty-four plants for each genotype were subjected to data collection after the three replications and harvesting time was four months after planting. Morphological data of height plants per replication for each cultivar were recorded for the different traits randomly selected as follow:

(i). Plant height $(\mathrm{PH})$ : Plant height was measured in centimeters from the ground level to the tip of the plant at fruit maturity (on $68^{\text {th }}$ day after transplanting for Tanya, P20 and Tengerou 97, and 5 days later after transplanting for Floradel).

(ii) Stem circumference (SC): Stem circumference was measured in centimeters between the ground level and the first branches at fruit maturity.

(iii) Leaf number (LN): Number of leaves per plant was counted at the time of harvest.

(iv) Leaf length (LL): The length of the $6^{\text {th }}$ leaf from the ground level for each plant was measured in centimeters at the time of harvest.

(v) Leaf width (LW): The width of the $6^{\text {th }}$ leaf from the ground level for each plant was measured in centimeters at the time of harvest.

(vi) Flower number (FIN): Total number of flowers from all the pickings was pooled and average number of flowers per plant was calculated.
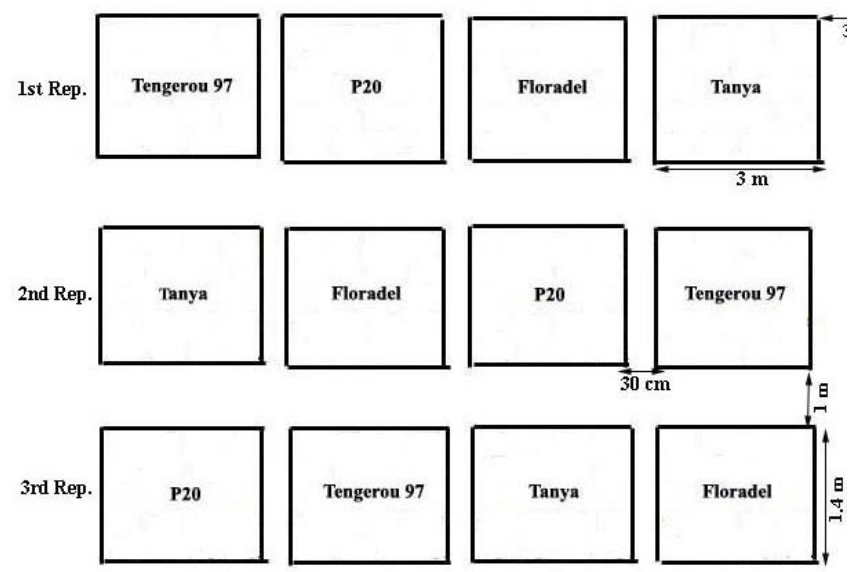

Figure 1. Schematic diagram showing the used randomized complete block design. $1^{\text {st }}$ Rep: first repetition; 2nd Rep: second repetition; 3rd Rep: third repetition.

(vii) Fruit number $(\mathrm{FrN})$ : Total number of harvested fruits from all the pickings was pooled and average number of fruits per plant was calculated.

(viii) Yield per cultivar (YC): Total number of harvested fruits from all the pickings was pooled and weighted in kilograms per area unit and per cultivar.

Visual observation of fruit morphology and color at the ripening time was also evaluated for the four cultivars.

\section{Data analysis}

The collected data were analyzed using GenStat Discovery 14 for the analysis of variance, SPSS (version 22.0) for descriptive statistics, coefficients of correlation and Principle Component Analysis. Hierarchical classification of the four cultivars using UPGMA method (Unweighted Pair Group Method using Arithmetic averages) from MSVP version 3.22. Analysis of variance was conducted for quantitative agro-morphological characters to determine the significance of the differences among the cultivars at 0.05 level. Descriptive statistics and coefficients of Pearson correlation were computed to determine the variability and the relationships between the cultivars based on the studied agro-morphological traits. Principal Component Analysis (PCA) and Hierarchical Cluster Analysis (HCA) were used to determine the extent of genetic variation and the percentage similarities within and between the cultivars. Eigen-values were obtained using the PCA and a dendrogram was generated using the HCA to display the relationships between the cultivars.

\section{RESULTS AND DISCUSSION}

\section{Fruit morphology and color evaluation}

Although almost the four cultivars showed a round form, diversity in fruit color is prominent (Figure 2). P20 cultivar was most remarkable, with blackish color, while the remaining cultivars showed a wide range of red color, Floradel cultivar being redder than Tanya and Tengerou97 respectively. 


\section{Mean values comparison}

A significant level of phenotypic variation was noticed among the 4 tomato cultivars for most of the quantitative traits considered (Table 1). Tanya cultivar showed the lowest mean plant height $(62.63 \mathrm{~cm})$ and the highest mean number of flowers (44.12), number of fruits (38.42) and yield per cultivar $(23.810 \mathrm{t} / \mathrm{ha})$. Tengerou97 showed the highest plant height $(93.08 \mathrm{~cm})$ and leaf length $(30.04 \mathrm{~cm})$ while the flower number (20.08), fruit number (17.04) and the yield per cultivar $(9.524 \mathrm{t} / \mathrm{ha})$ was the lowest in this cultivar. P20 cultivar is the first in leaf length $(30.00 \mathrm{~cm})$ and width $(21.79 \mathrm{~cm})$, while it is the last in stem circumference (4.925). Floradel cultivar showed the highest stem circumference $(7.362 \mathrm{~cm})$ and leaf number $(21.00)$, while it showed the lowest leaf width $(17.62 \mathrm{~cm})$.

\section{Analysis of variance}

Although analysis of variance (ANOVA) showed that all eight traits had a very high level of difference among tomato lines $(\mathrm{P}<0.001)$, the largest variation was recorded for plant height, flower number, yield per cultivar and fruit number in which the widest range of variation was also observed (Table 1). In this regard, plant height, stem circumference, leaf width, flower number, and fruit number are the traits that have significantly differentiated the four tomato cultivars. However, leaf number and leaf length significantly distinguished Tanya and Floradel cultivars but not P20 and Tengerou97. Yield per cultivar significantly differentiated Tanya and Tengerou97 cultivars but not P20 and Floradel.

\section{Correlations between agro-morphological traits}

Correlations between 8 agro-morphological traits are presented in Table 2. A significant positive correlation was observed between plant height and stem circumference, leaf number, and leaf length, between stem circumference and leaf number, between flower number and fruit number and yield per cultivar, and between fruit number and yield per cultivar.

\section{Cluster analysis}

Cluster analysis using Euclidian data square-root transformed distances based on the 8 agro-morphological characteristics divided cultivars into three major groups tending to show 4 groups corresponding to the four cultivars (Figure 2). The first and the third clusters correspond to Tanya and P20 cultivars respectively. The second group comprises of Tengerou97 and Floradel cultivars which seem to correspond to two separate clusters and tending to be close to P20 than Tanya cultivar.

Table 2. Pearson correlation coefficients between the 8 agromorphological traits of the 4 tomato cultivars

\begin{tabular}{|c|c|c|c|c|c|c|c|c|}
\hline & PH & SC & $\mathbf{L N}$ & $\mathbf{L L}$ & $\mathbf{L W}$ & FIN & FrN & YC \\
\hline$\overline{\mathrm{PH}}$ & 1 & & & & & & & \\
\hline $\mathrm{SC}$ & $0.629^{*}$ & 1 & & & & & & \\
\hline LN & $0.756^{* *}$ & $\mathbf{0 . 8 5 3}^{* *}$ & 1 & & & & & \\
\hline LL & $0.650^{*}$ & -0.034 & 0.321 & 1 & & & & \\
\hline LW & -0.402 & $-0.801^{* *}$ & $-0.592^{*}$ & 0.328 & 1 & & & \\
\hline FIN & $-0.970^{* *}$ & -0.752 & $-0.817^{*}$ & -0.558 & 0.530 & 1 & & \\
\hline FrN & $-0.963^{* *}$ & -0.728 & $-0.814^{*}$ & $-0.621^{*}$ & 0.468 & $0.992^{* *}$ & * $\quad 1$ & \\
\hline $\mathrm{YC}$ & $-0.938^{* *}$ & -0.537 & $-0.641^{*}$ & $-0.770^{* * *}$ & 0.218 & $0^{2} 923^{* *}$ & * $0.951^{* *}$ & 1 \\
\hline
\end{tabular}

Note: In bold are coefficients showing significant correlations

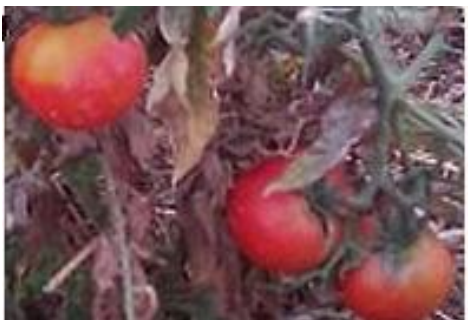

A

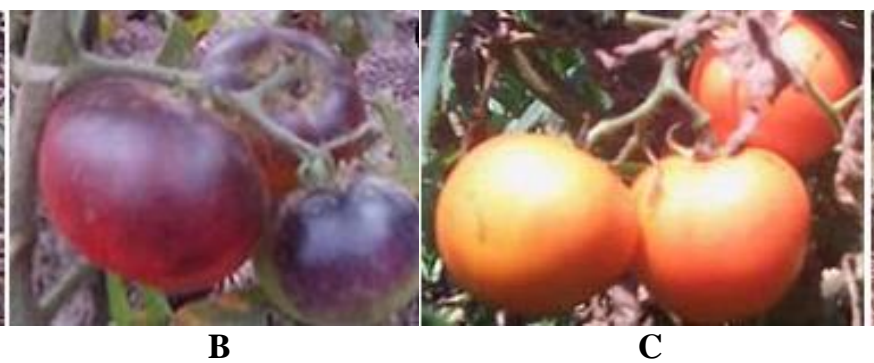

B

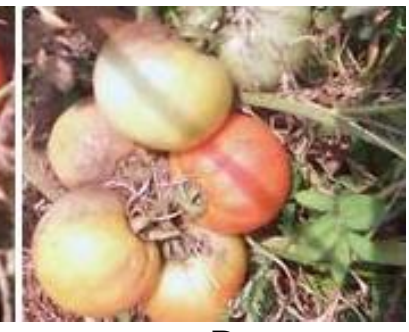

D

Figure 2. Photos showing fruit morphology and color of the four tomato cultivars. A. Floradel; B. P20; C. Tanya; D. Tengerou97

Table 1. Mean values per tomato cultivar for the eight quantitative traits

\begin{tabular}{|c|c|c|c|c|c|c|c|c|}
\hline \multirow{2}{*}{ Variety } & \multicolumn{8}{|c|}{ Agro-morphological traits } \\
\hline & $\mathbf{P H}$ & SC & $\mathbf{L N}$ & $\mathbf{L L}$ & $\mathbf{L W}$ & FIN & FrN & YC \\
\hline Tanya & $62.63 d$ & $5.287 \mathrm{c}$ & $18.25 \mathrm{c}$ & $28.04 b$ & $21.04 b$ & $44.12 \mathrm{a}$ & $38.42 \mathrm{a}$ & $23.810 \mathrm{a}$ \\
\hline Tengerou97 & $93.08 \mathrm{a}$ & $6.383 b$ & $19.88 b$ & $30.04 \mathrm{a}$ & $19.96 \mathrm{c}$ & $20.08 \mathrm{~d}$ & $17.04 d$ & $9.524 c$ \\
\hline $\mathrm{P} 20$ & $87.21 \mathrm{c}$ & $4.925 \mathrm{~d}$ & $19.29 b$ & $30.00 \mathrm{a}$ & $21.79 \mathrm{a}$ & $29.87 b$ & $25.92 b$ & $14.286 b$ \\
\hline Floradel & $91.12 \mathrm{~b}$ & $7.362 \mathrm{a}$ & $21.00 \mathrm{a}$ & $28.62 b$ & $17.62 \mathrm{~d}$ & $21.75 \mathrm{c}$ & $20.17 \mathrm{c}$ & $14.444 b$ \\
\hline Mean & 83.51 & 5.989 & 19.60 & 29.18 & 20.10 & 28.955 & 25.39 & 15.516 \\
\hline Range & $59-96$ & $4.5-7.6$ & $17-22$ & $27-32$ & $17-24$ & $15-48$ & $10-42$ & $8.33-25.00$ \\
\hline S.E & 12.79 & 1.02 & 1.12 & 0.99 & 1.52 & 10.00 & 8.52 & 5.51 \\
\hline F.value & 1342.49 & 642.94 & 27.06 & 24.59 & 66.98 & 739.75 & 484.06 & 1748.04 \\
\hline P.value & $<0.001$ & $<0.001$ & $<0.001$ & $<0.001$ & $<0.001$ & $<0.001$ & $<0.001$ & $<0.001$ \\
\hline
\end{tabular}

Note: In a column, letters indicate number of homogenous groups, numbers with same letter (s) do not differ significantly at $\mathrm{P}=0.05$ 


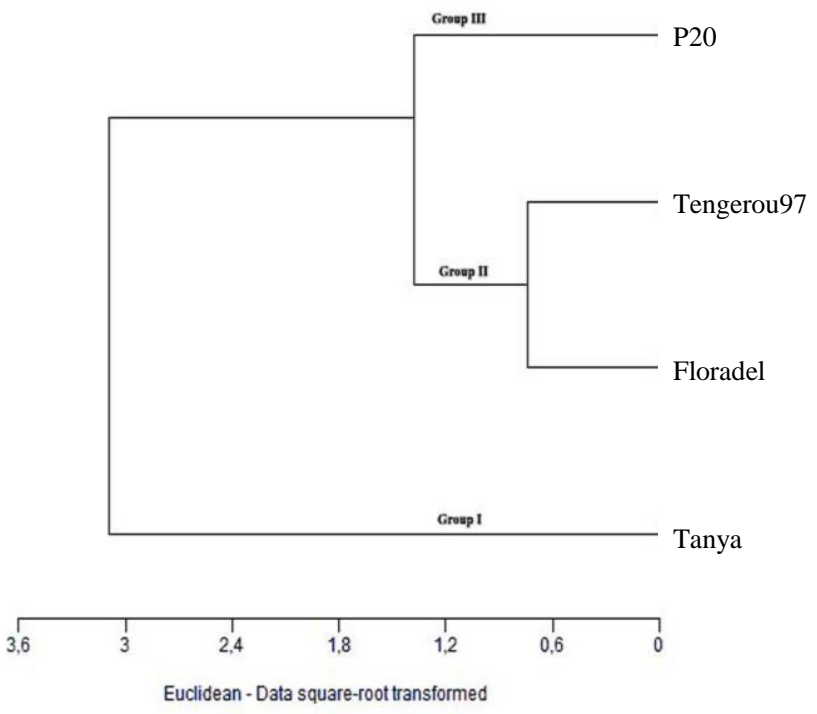

Figure 2. Dendrogram from Hierarchical Cluster Analysis of the four tomato cultivars based the eight agro-morphological traits

Table 3. Values of two principal components for traits of tomato cultivars

\begin{tabular}{lccc}
\hline Traits & PC1 & PC2 & PC3 \\
\hline Plant height & -0.929 & 0.164 & -0.164 \\
Stem circumference & -0.661 & -0.641 & 0.156 \\
Leaf number & -0.774 & -0.234 & 0.495 \\
Leaf length & -0.609 & 0.635 & 0.347 \\
Leaf width & 0.409 & 0.855 & 0.114 \\
Flower number & 0.971 & -0.006 & 0.191 \\
Fruit number & 0.964 & -0.096 & 0.175 \\
Yield per cultivar & 0.897 & -0.352 & 0.161 \\
& & & \\
Eigen values & 5.114 & 1.760 & 0.523 \\
Percent of variance & 63.927 & 22.004 & 6.534 \\
Cumulative percentage & 63.927 & 85.931 & 92.465 \\
\hline
\end{tabular}

\section{Principal component analysis (PCA)}

Principal component analysis (PCA) performed with the 8 agro-morphological traits of the four tomato cultivars is presented in Table 3. The first three principal components of $S$. lycopersicum accounted for $92.465 \%$ of the total variation with Eigenvalues of 5.114, 1.760, and 0.523 and percent variance of $63.927,22.004$, and $6.534 \%$, respectively. The PC1 shows that all the 8 agromorphological traits have effects on tomato cultivar grouping. The PC2 showed positive correlation with plant height, leaf length, and leaf width, and negative correlation with stem circumference, leaf number, flower number, fruit number, and yield per cultivar. PC3 showed positive correlation with all the agro-morphological traits except plant height.

\section{Discussion}

Tomato is intensively cultivated in low altitude regions (800 to $1200 \mathrm{~m}$ ) of Burundi which yields three-quarters of the national production of tomato fruits (reviewed by Nihorimbere et al. 2010). However, diversity based on neither morphological, biochemical nor molecular parameters among different cultivars of this important crop plant has not yet envisaged.

In the present study, although their fruits have a round form, the four cultivars manifested different fruit color, a blackish (P20) and varying degrees of red color (Floradel, Tanya, and Tengerou97). Differential fruit color in tomato is often associated with a possible diversity in carotenoids content, such as lycopene and others as exampled by a recent finding (Yoo et al. 2017). Assessment of agromorphological diversity of $S$. lycopersicum cultivars also revealed variation in the considered traits as they all distinguished the studied cultivars. Mean values, analysis of variance and principal component analysis showed the variability in cultivated tomato. Interestingly, Tanya cultivar shows the lowest plant height but the highest flower number, fruit number and yield per cultivar. P20 cultivar followed Tanya in plant height and plant yield parameters (flower number, fruit number, and yield per cultivar) and similar findings were recently observed in tomato (Tuan and Mao 2015). This was corroborated by a significant negative correlation between plant height and flower, fruit number and yield per cultivar overall. However, our results are inconsistent with those of Campos de Melo et al. (2015) in which plant height positively correlated with fruit yield, showing that agromorphological variability in cultivated tomato may be genotype-and environment-dependent. On the other hand, Floradel and Tengerou97 cultivars have the highest stem circumference (i.e. stem diameter) and leaf number. In this work, stem circumference could be considered as a strong indicator of water status of the plant (Meng et al. 2017), while leaf number is consistent with plant height.

Thus, Tanya and P20 cultivars are agronomically the most promising at the yield level, while Floradel and Tengerou97 can be exploited in tomato plant ecophysiology studies. The four cultivars should then be exploited in tomato breeding and improvement programs. Moreover, this large variability among four cultivars of tomato was depicted by cluster analysis which showed almost four clusters corresponding to one cluster for each cultivar, though Tengerou97 and Floradel tend to be grouped together. Different other characters should, however, be involved in the analysis to completely distinguish the two tomato cultivars. On the basis of the considered agro-morphological traits, this large variation indicates a high level of heterogeneity in four tomato cultivars cultivated in western Burundi. In recent works using varied traits, morphological variation in tomato genotypes was also revealed by Kouam et al. 2018; Bernousi et al. 2011; Chime et al. 2017; Vishwanath et al. 2014; Chávez-Servia et al. 2018; Henareh et al. 2015; and Bhattarai et al. 2016.

Relationships between different agro-morphological traits were depicted by correlation analysis. As expected, plant height showed significant positive correlation with stem circumference, leaf number, and leaf length. As mentioned above for Tanya, overall cultivars also showed 
significant negative correlations between plant height and flower number, fruit number and yield per cultivar. This indicates that plant height has no direct effect on yield parameters in the four cultivars. Nonetheless, flower number and fruit number per plant, and yield per cultivar showed strong positive correlations as well as fruit number per plant and yield per cultivar. This was also found by Ritong et al. (2018) in the case of fruit number and yield. This information indicates that all produced flowers per plant almost developed into fruits.

Based on the PC1, principal component analysis showed that all the eight agro-morphological traits participated in grouping tomato cultivars; particularly flower number, fruit number, plant height, and yield per cultivar, leaf width having the lowest influence on total variation. These characters could be exploited as useful agro-morphological markers to discriminate tomato genotypes and are expected to provide high level of gene transfer during breeding programs in other crop plants such as rice (Gana et al. 2013).

Overall, the present work showed noticeable agromorphological variability among the tomato cultivars. Indeed, all the considered agro-morphological traits, particularly plant height, flower number, fruit number and yield per cultivar, significantly discriminated the four tomato cultivars, as indicated by one-way analysis of variance, mean values per cultivar, cluster and PCA. Therefore, findings presented in the present study allowed the differentiation of tomato cultivars with distinct fruit color and agro-morphological descriptors that could be included in the breeding and improvement of this important crop plant.

\section{ACKNOWLEDGEMENTS}

Authors would like to acknowledge the ISABU authorities for kindly providing tomato seed samples and field for nursery and transplanting during the research experiments.

\section{REFERENCES}

Agarwal S, Rao AV. 2000. Tomato lycopene and its role in human health and chronic diseases. CMAJ 163 (6): 739-744.

Agong SG, Schittenhelm S, Friedt W. 2001. Genotypic variation of Kenyan tomato (Lycopersicon esculentum L.) germplasm. J Food Technol Afric 6 (1): 13-17.

Agyare RY, Akromah R, Abdulai MS. 2016. Assessment of genetic diversity in pepper (Capsicum sp.) landraces from Ghana using agromorphological characters. Amer J Exp Agricult 12 (1): 1-16.

Al-Aysh F, Al-Serhan M, Adnan AS, Mohammad A-N, Kutma H. 2012. Study of genetic parameters and character interrelationship of yield and some yield components in tomato (Solanum lycopersicum L.). Intl J Genet 2 (2): 29-33.

Arumuganathan K, Earle ED. 1991. Estimation of nuclear DNA content of plants by flow cytometry. Plant Mol Biol Report 9: 229-241.

Azimi MH, Tahernezhad Z, Zamani MJ. 2016. Genetic variation within Iranian Iris species using morphological traits. Intl J Horticult Sci Technol 3 (1): 89-98.

Bellatreche A, Mahmad MY, Kaouadji Z, Gaouar SBS. 2017. Agromorphological diversity of some accessions of bread wheat (Triticum aestivum) in western Algeria. Biodiv 18 (1): 409-415.
Bernousi I, Emami A, Tajbakhsh M, Darvishzadeh R, Henareh M. 2011. Studies on Genetic Variability and Correlation among the Different Traits in Solanum lycopersicum L. Not Botan Hort Agrobotan ClujNapoca 39 (1): 152-158.

Bhattarai K, Louws FJ, Williamson JD, Panthee DR. 2016. Diversity analysis of tomato genotypes based on morphological traits with commercial breeding significance for fresh market production in eastern USA. Austral J Crop Sci 10 (8): 1098-1103.

Blanca J, Cañizares J, Cordero L, Pascual L, José Diez M, Nuez F. 2012. Variation revealed by SNP genotyping and morphology provides insight into the origin of the Tomato. PLoS ONE. 7 (10): e48198, DOI: 10.1371/journal. pone.0048198.

Boros L, Wawer A, Borucka K. 2014. Morphological, phonological and agronomical characterization of variability among common bean (Phaseolus vulgaris L.) local populations from the national center for plant genetic resources: Polish genebank. J Horticult Res 22 (2): 123130.

Caldo RA, Sebastian LS, Hernandez JE. 1996. Morphological-based genetic diversity analysis of ancestral lines of Philippine rice cultivars. Philipp. J. Crop Sci 21 (3): 86-92.

Campos de Melo AP, Fernandes PM, Venturoli F, Silva-Neto C de M, Neto AR. 2015. Morphoagronomic characterization of tomato plants and fruit: A multivariate approach. Adv Agricult 2015, Article ID 572321: 1-6. DOI: 10.1155/2015/572321.

Chávez-Servia JL, Vera-Guzmán AM, Linares-Menéndez LR, CarrilloRodríguez JC, Aquino-Bolaños EN. 2018. Agromorphological Traits and Mineral Content in Tomato Accessions from El Salvador, Central America. Agronomy. 8, 32. DOI: 10.3390/agronomy8030032.

Chime AO, Aiwansoba RO, Osawaru ME, Ogwu MC. 2017. Morphological evaluation of tomato (Solanum lycopersicum Linn.) Cultivars. Mak J Sci 21/2: 97-106.

FAO (Food and Agriculture Organization of the United Nations). 2017. FAOSTAT Database. FAO, Rome. http: //faostat3.fao.org/

Fuseini Z. 2010. Occurrence and control of seedborne pathogenic fungi of tomato (Lycopersicon esculentum Mill.) In: Seeds from Five AgroEcological Zones of Ghana using Plant Extracts; A thesis submitted to the College of Agriculture and Natural Resources (CANR). Kwame Nkrumah University of Science and Technology, Kumasi.

Gana AS, Shaba SZ, Tsado EK. 2013. Principal component analysis of morphological traits in thirty-nine accessions of rice (Oryza sativa L.) grown in a rainfed lowland ecology of Nigeria. J Plant Breed Crop Sci 5: 120-126.

Henareh M, Dursun A, Mandoulakani BA. 2015. Genetic diversity in tomato landraces collected from Turkey and Iran revealed by morphological characters. Acta Sci Pol Hortorum Cultus 14 (2): 8796.

Isah AS, Amans EB, Odion EC, Yusuf AA. 2014. Growth rate and yield of two Tomato varieties (Lycopersicon esculentum Mill) under green manure and NPK Fertilizer rate Samaru Northern Guinea Savanna. Int J Food Sci Nutr 932759: 1-8. DOI: 10.1155/2014/932759.

Kidaha LM, Alakonya AE, Nyende AB. 2015. Morphological characters of Guava landraces in Western and Coastal Kenya. Amer J Exp Agricult 9 (6): 1-11.

Kouam EB, Dongmo JR, Djeugap JF. 2018. Exploring morphological variation in tomato (Solanum lycopersicum): A combined study of disease resistance, genetic divergence and association of characters. Agric Trop Subtrop 51 (2): 71-82.

Mazzucato A, Papa R, Bitocchi E, Mosconi P, Nanni L, Negri V, Picarella ME, Siligato F, Soressi GP, Tiranti B, Veronesi F. 2008. Genetic diversity, structure and marker-trait associations in a collection of Italian tomato (Solanum lycopersicum L.) landraces. Theor Appl Genet 116 (5): 657-669.

Meng Z, Duan A, Chen D, Dassanayake KB, Wang X, Liu Z, Liu H, Gao S. 2017. Suitable indicators using stem diameter variation-derived indices to monitor the water status of greenhouse tomato plants. PLoS ONE 12 (2): e0171423. DOI: 10.1371 journal.pone.0171423.

Mwirigi PN, Kahangi EM, Nyende AB, Mamati EG. 2009. Morphological variability within the Kenyan yam (Dioscorea spp.). J Appl Biosci 16: 894-901.

Neya FB, Koita K, Elise S, Zagre BM, Nana AT, Burow MD, Sankara P. 2018. Agro-morphological diversity of six peanuts (Arachis hypogaea L.) breeding lines from three geographical areas. J Exp Agricult Intl $19(5): 1-12$.

Ngezahayo F, Manirakiza L, Manirakiza E. 2018. Impact of altitude on morphological traits-based phenotypic variability in Bidens pilosa L. from three natural regions of Burundi. Ann Res Rev Biol 28 (3): 1-11. 
Nihorimbere V, Ongena M, Cawoy H, Brostaux Y, Kakana P, Jourdan E, Thonart P. 2010. Beneficial effects of Bacillus subtilis on field-grown tomato in Burundi: Reduction of local Fusarium disease and growth promotion. Afric J Microbiol Res 4 (11): 1135-1142.

Ogwu MC, Osawaru ME, Aiwansoba RO, Iroh RN. 2016. Status and Prospects of Vegetables in Africa. Proceedings of NTBA/NSCB Joint Biodiversity Conference on MDGs to SDGs: Toward Sustainable Biodiversity Conservation in Nigeria held at University of Ilorin, Nigeria.

Osei MK, Bonsu KO, Agyeman A, Choi HS. 2014. Genetic diversity of tomato germplasm in Ghana using morphological characters. Intl J Plant Soil Sci 3 (3): 220-231.

Reddy BR, Reddy MP, Begum H, Sunil N. 2013. Genetic diversity studies in tomato (Solanum lycopersicum L.). J Agricult Vet Sci 4: 53-55.

Ritonga AW, Chozin MA, Syukur M, Maharijiya A, Sobir. 2018. Genetic variability, heritability, correlation, and path analysis in tomato (Solanum lycopersicum) under shading condition. Biodiversitas 19 (4): 1527-1531.

Roughani A, Miri SM, Hassandokht MR, Moradi P, Abdossi V. 2018. Morphological variation of some Lepidium draba and L. latifolium populations. Taiwania 63 (1): 41-48.
Saka M, Ahoton LE, Ezin V, Quenum F, Ayena M. 2017. Agromorphological assessment of local cultivars of nightshade (Solanum macrocarpon L.) in Benin. J Exp Agricult Intl 15 (3): 1-14.

Shinwari ZK, Rehman H, Rabbani MA. 2014. Morphological traits based genetic diversity in safflower (Carthamus tinctorius L.). Pak J Bot 46 (4): 1389-1395.

Tuan NM, Mao NT. 2015. Effect of plant density on growth and yield of tomato (Solanum lycopersicum L.) at Thai Nguyen, Vietnam. Intl J Plant Soil Sci 7 (6): 357-361.

Vishwanath K, Rajendra Prasad S, Pallavi HM, Prasanna KPR. 2014. Characterization of tomato cultivars based on morphological traits. Ann Plant Sci 3 (11): 854-862.

Yadav A, Tandan N, Singh R. 2017. Morphological based genetic variability analysis and clustering of tomato. World J Pharmaceut Med Res 3 (6): 255-261.

Yoo HJ, Park WJ, Lee G-M, Oh C-S, Yeam I, Won D-C, Kim CK, Lee JM. 2017. Inferring the genetic determinants of fruit colors in tomato by carotenoid profiling. Molecules 22 (764): 1-14. 